Edição de Março 2007, vol. 88 (3), págs. 340-345

No artigo original "Efeito do Bisoprolol sobre a Função Cardíaca e o Exercício em Pacientes com Insuficiência Cardíaca”, páginas 340-345, considerar correto o trecho seguinte em substituição ao publicado na página 341: “(...) Os efeitos do bisoprolol, bloqueador beta 1 seletivo, sobre a capacidade de exercício na insuficiência cardíaca não foram avaliados de maneira sistemática em casuísticas representativas e recentes."

\title{
Edição de Janeiro 2008, vol. 90 (1), págs. 31-36
}

No artigo original "Avaliação da Relação Neutrófilos/Linfócitos em Pacientes com Suspeita de Síndrome Coronariana Aguda", páginas 31-36, dos autores Ana Denise Zazula, Daniel Précoma-Neto, Aline Maria Gomes, Heidi Kruklis, Giovano Franco Barbieri, Rafael Yared Forte, André Ribeiro Langowiski, Giuseppe Facin, Luiz Cesar Guarita de Souza, José Rocha Faria Neto, considerar correta a grafia Luiz César Guarita-Souza para o nome do autor.

\section{Edição de Março 2008, vol. 90 (3), Sumário}

Considerar os autores corretos para a correlação anátomo-clínica "Homem de 43 anos com Alucinação, Rigidez de Nuca, Convulsão e Ausculta de Disfunção Completa de Valva Aórtica", páginas 224-230: Vitor Emer Egypto Rosa, Luciana Sacilotto, Carlos Osvaldo Teixeira, Maria Aparecida Barone Teixeira. 